\title{
A INFLUÊNCIA DAS PROPRIEDADES FÍSICO-MECÂNICAS NA DURABILIDADE DO CONCRETO PIGMENTADO
}

\author{
CONSANI, CAMILA PINHEIRO \\ Mestranda da FAUUSP \\ Universidade de São Paulo \\ São Paulo - Brasil \\ camila.consani@usp.br
}

\author{
OLIVEIRA, FABIANA LOPES DE \\ Docente da FAUUSP \\ Universidade de São Paulo \\ São Paulo - Brasil \\ floliveira@usp.br
}

\section{RESUMO}

O concreto aparente pigmentado permite agregar valor estético com ampla variedade de cores e tons além do cinza aos projetos, possibilitando a realização de obras relevantes para a arquitetura contemporânea, além de conter o custo de manutenção de pintura e substituir utilização de revestimento. Porém, a produção do concreto com pigmento necessita de rigoroso controle desde a escolha dos insumos empregados na mistura até a cura do concreto para obter um resultado satisfatório, levando em consideração que o aspecto visual da cor é um dos principais objetivos deste material. Desta forma, o presente artigo tem por objetivo contribuir por meio de análises dos ensaios de caracterização do concreto no estado fresco e endurecido mediante a avaliação das propriedades físico-mecânicas de concretos sem e com pigmentos inorgânicos sintéticos à base de hidróxido de ferro, óxido de cobalto e cromo adicionados à mistura com teor de $5 \%$ da massa de cimento. De acordo com normas direcionadas ao concreto autoadensável e aos ensaios de absorção de água, índice de vazios e massa específica; absorção de água por capilaridade e resistência à compressão axial em corpos de prova cilíndricos de $10 \mathrm{~cm}$ x $20 \mathrm{~cm}$ (diâmetro x altura) foi possível analisar os concretos produzidos. Com os resultados obtidos nos ensaios e as análises desenvolvidas, concluiu-se que a dosagem adotada foi satisfatória em relação à resistência mecânica e a durabilidade, contribuindo para a qualidade da estética do concreto pigmentado.

Palavras-chave: Concreto, Pigmento, Dosagem, Resistência, Durabilidade.

\begin{abstract}
The apparent pigmented concrete allows adding esthetic value with broad variety of colors and shades, in addition to gray, to the projects, enabling performance of relevant works for the modern architecture, in addition to containing the painting maintenance cost and replacing the use of lining. However, production of pigmented concrete needs strict control since the selection of the inputs used in the mixture to the concrete cure, in order to obtain a satisfactory result, taking into consideration that the visual aspect of the color is one of the main goals of this material. Thus, the purpose of the present article is to contribute by means of analyses of the characterization tests of the fresh and the hardened concrete upon assessment of the physical-mechanical properties of concretes without and with iron hydroxide, cobalt oxide and chromium based synthetic organic pigments added to the mixture with content of 5\% cement mass. According to the standards for self-consolidating concrete and the tests of water absorption, void index and specific gravity; water absorption by capillarity and axial compressive strength in cylindrical specimens of $10 \mathrm{~cm} \times 20 \mathrm{~cm}$ (diameter $\mathrm{x}$ height), it was possible to analyze the produced concrete. With the results obtained in the testing and the developed analyses, it was concluded that the adopted dosage was satisfactory in relation to mechanical resistance and durability, contributing to the esthetic quality of the pigmented concrete.
\end{abstract}

Keywords: Concrete, Pigment, Dosage, Resistance, Durability. 


\section{INTRODUÇÃO}

O grande uso do concreto na construção civil em pequenas e grandes obras para fins estruturais e estéticos se deve, principalmente, pela versatilidade e vantagens oferecidas por este material. O principal motivo do vasto consumo é o equilíbrio entre a qualidade e o custo competitivo. Além disto, possibilita variabilidade de formas e apresentar alta resistência mecânica que relacionada à durabilidade, promove o uso em diversas construções (PIOVESAN, 2009).

Embora o concreto seja globalmente utilizado, este material ainda é censurado por seu aspecto pouco atrativo, e com irrisório valor arquitetônico e estético, principalmente quando se trata do concreto aparente. Por estar relacionado a um aspecto insípido devido a cor acizentada, alguns profissionais relutam em especificá-lo como objeto de criatividade em seus projetos, optando por outros tipos de materiais (AGUIAR, 2006).

Devido à crescente exigência do mercado nacional e internacional, como também, a necessidade de inovações, o setor encontra-se em um processo de modernização. A padronização de procedimentos, racionalização de atividades, redução de desperdícios e o desenvolvimento de novos materiais e produtos, com tecnologia avançada, fazem parte deste contexto (PASSUELO, 2004).

Incorporado a este panorama de inovação o concreto pigmentado surgiu apresentando versatilidade cromática, possibilitando novas criações e valorização da estrutura em concreto aparente. Portanto, o uso deste material almeja destacar sua utilização não só como um elemento estético, mas também, preservar suas propriedades físico-mecânicas de modo a contribuir para a durabilidade. A produção do concreto pigmentado é obtido por meio da associação de pigmentos orgânicos ou inorgânicos ao cimento Portland branco ou cinza permitindo a sua confecção em diversas cores. A mistura ocasiona um material moldável, mas que exige um rigoroso controle durante a dosagem, preparo e aplicação para obter um resultado satisfatório, levando em consideração que o aspecto visual da cor é um dos principais objetivos deste material (DE MENDONÇA et al., 2018).

O concreto pigmentado pode ser utilizado em diversos tipos de construções, sendo empregado em pisos, móveis urbanos, fachadas de edifício, paredes e painéis, o que permite dispensar a aplicação de revestimento. Este benefício pode representar economia para algumas edificações, pela isenção do processo de chapisco, emboço, reboco, pinturas, texturas e azulejos durante a obra, e assim, possibilitar um diferencial estético e arquitetônico. Além de possuir vida útil igual ou superior ao concreto convencional, de 50 anos, o concreto pigmentado apresenta conservação mais elevada do que revestimento de tintas, que carece de intervenções periódicas a cada 5 anos (SOUSA et al., 2018;VALENÇA et al., 2017).

Para que o concreto pigmentado seja inserido de forma ampla e confiável no setor da construção civil, é imprescindível desenvolver um conhecimento amplo de métodos e procedimentos tecnológicos para melhor aplicação e adequação do material. Deste modo, será possível caracterizar suas propriedades e avaliar os impactos das mudanças em relação à resistência e durabilidade, como também, evitar manifestações patológicas decorrentes de falhas ao longo do processo produtivo e durante a sua utilização (PIOVESAN, 2009).

Atualmente diversas obras com este material podem ser encontradas em países como Suíça, Polônia, Áustria, Espanha, Portugal, África do Sul, Coréia, México, Colômbia, Chile e Brasil. São destacados exemplos de obras em concreto pigmentado com sua localização e ano de construção na Figura 1.

Figura 1 - Exemplos de obras em concreto pigmentado: (a) Hotel ESO, Cerro Paranal, Chile em 2002; (b) Bodega

Antión, La Rioja, Espanha no ano 2007; (c) Museu da Aviação e Parque de Exposições de Aviação Lotnictwa Polskiego, Cracóvia, Polônia em 2010; (d) Praça das Artes, São Paulo, Brasil no ano de 2012.
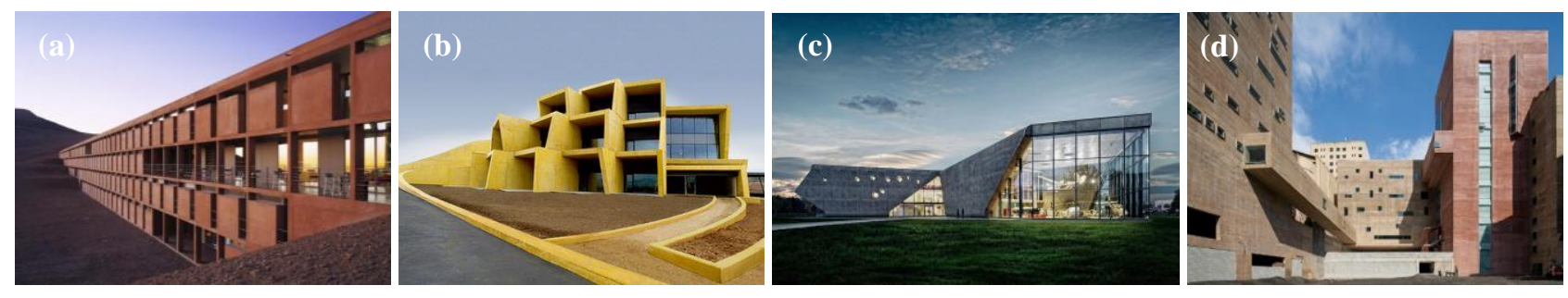

Fonte: Lanxess.

Portanto, o presente artigo busca contribuir como estudo do concreto pigmentado, analisando a influência de pigmentos inorgânicos à base de hidróxido de ferro, óxido de cobalto e cromo na mistura do concreto. Para isto, analisar-se-á resultados dos ensaios de caracterização do concreto no estado fresco e endurecido, mediante a avaliação das propriedades físico-mecânicas de concretos sem e com pigmentos inorgânicos sintéticos. 


\section{PROGRAMA ESPERIMENTAL}

\subsection{Materiais}

Com o objetivo de produzir um concreto aparente pigmentado de alta resistência e qualidade, optou-se por um tipo de concreto especial, o concreto autoadensável (CAA) de acordo com a ABNT NBR 15823-1:2017. Para sua produção utilizou-se os mesmos materiais dos outros tipos de concretos, com a diferença apenas no acréscimo das adições mineral e aditivos na mistura.

As amostras sem e com pigmento foram produzidas utilizando cimento Portland cinza de origem nacional tipo CPII E 40 da Votorantim (por ter adição de escória de alto forno, possibilita menor calor de hidratação o que colabora para um tempo maior do início de pega favorecendo a produção do CCA); dois tipos de agregado miúdo, sendo um de origem artificial de calcário da VC - Araçariguama e outro origem de natural de quartzo da Minermix; dois tipos de agregado graúdo, ambos de origem calcária, sendo Brita 0 e 1 da VC - Araçariguma; e água fornecida pelo sistema público de abastecimento de água de São Paulo - SP com condições de potabilidade.

Optou-se pela adição de sílica ativa da Tecnosil na mistura com o propósito de diminuir a porosidade e fortalecer a microestrutura do concreto. Para promover a fluidez e a trabalhabilidade do concreto utilizou-se três tipos de aditivos: o plastificante polifuncional - redutor de água Mira 94 da GCP Applied Technologies; o superplastificante - alto poder de redução de água ADVA FLOW 422 da GCP Applied Technologies classificado como tipo SP II; e o modificador de viscosidade - Levasil CB 45-A da Akzo Nobel que é uma dispersão aquosa de sílica coloidal.

\subsubsection{Pigmentos}

Os pigmentos adicionados à mistura foram do tipo inorgânico sintético em pó da Lanxess à base de hidróxido de ferro (amarelo), óxido de cobalto (azul) e cromo (verde). A porcentagem estipulada de pigmento em relação a massa de cimento foi de $5 \%$ em relação à massa de cimento devido ao ponto de saturação da cor em relação a dosagem. $\mathrm{O}$ acréscimo de pigmento acima do ponto de saturação não promoverá a intensificação cromática e poderá contribuir para a redução da resistência à compressão do concreto (COELHO et al., 2002). Isto porque, o aumento de finos na mistura pode contribuir para a redução da resistência mecânica do concreto apresentando menor durabilidade, como também, o aumento do custo do concreto sem trazer benefícios em sua coloração.

As informações sobre os pigmentos empregados na mistura estão na Tabela 1 e Figura 2.

Tabela 1 - Informações sobre os pigmentos inorgânicos sintéticos utilizados.

\begin{tabular}{c|c|c|c}
\hline Cor do pigmento & Componente & Fórmula & \multirow{2}{*}{ Estado físico } \\
\cline { 1 - 3 } Amarelo & Hidróxido de ferro & Fe OOH & \multirow{2}{*}{ Sólido (pó) } \\
\cline { 1 - 3 } Azul & Óxido de cobalto & $\mathrm{Co}(\mathrm{Al}, \mathrm{Cr})_{2} \mathrm{O}_{4}$ & \\
\hline Verde & Óxido de cromo & $\mathrm{Cr}_{2} \mathrm{O}_{3}$ & \\
\hline
\end{tabular}

Fonte: Autores.

Figura 2 - Proporção do volume dos pigmentos utilizados na mistura.

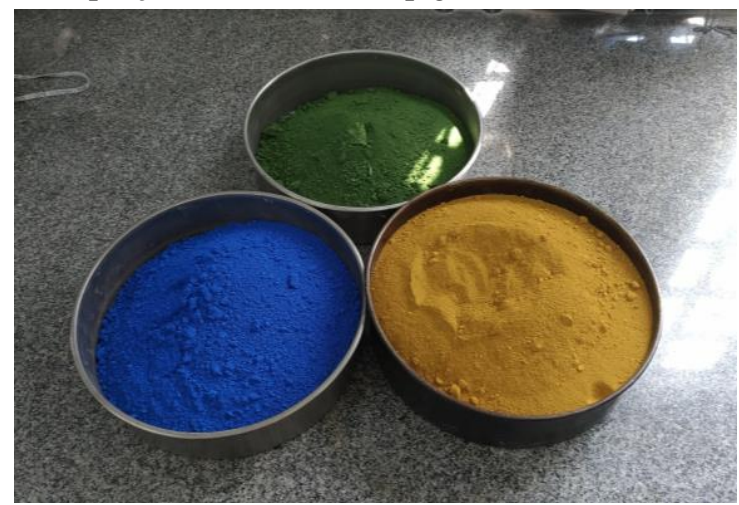

Fonte: Autores. 


\subsection{Método}

\subsubsection{Dosagem do concreto em laboratório}

É de extrema importância para o concreto pigmentado considerar a homogeneidade da cor no volume total a ser concretado, para isto, na dosagem foram empregados materiais do mesmo fornecedor, lote e quantidade, assim como, equipamentos apropriados para possibilitar uma mistura homogênea. Além do concreto com pigmento, foi sucedida a dosagem do concreto sem pigmento sendo utilizado como uma base de comparação, visto que a única diferença entre ambos foi a incorporação de $5 \%$ de pigmento, ou seja, o mesmo traço foi empregado para todas as amostras concretadas.

O traço adotado para o concreto autoadensável foi resultado de um amplo e prévio estudo de dosagem, realizado em laboratório envolvendo mais de 60 misturas distintas com o intuito de atingir fck de $60 \mathrm{MPa}$ aos 28 dias, com a relação água / cimento em 0,47 para todos os concretos sem e com pigmento nas cores amarela, azul e verde. Assim sendo, o traço determinado para as amostras foi $1: 2,37: 2,57: 0,47$ (cimento : areia : brita : água). Na Tabela 2 é possível observar os insumos empregados na concretagem das amostras e a quantidade.

Tabela 2 - Traço adotado para a concretagem em materiais secos por $\mathrm{m}^{3}$ de concreto.

\begin{tabular}{cc}
\hline Materiais & Quantidade \\
\hline Consumo de cimento & $370 \mathrm{Kg}$ \\
\hline Areia artificial de calcário & $351 \mathrm{Kg}$ \\
\hline Areia natural de quartzo & $527 \mathrm{Kg}$ \\
\hline Brita 0 & $570 \mathrm{Kg}$ \\
\hline Brita 1 & $380 \mathrm{Kg}$ \\
\hline Água livre + Água de umidade das areias + Água de amassamento & $174 \mathrm{Kg}$ \\
\hline Pigmento - 5,0\% & $18,5 \mathrm{Kg}$ \\
\hline Adição de sílica ativa & $65 \mathrm{Kg}$ \\
\hline Aditivo plastificante polifuncional - $0,4 \%$ & $1,5 \mathrm{Kg}$ \\
\hline Aditivo superplastificante - 1,2\% & $4,5 \mathrm{Kg}$ \\
\hline Aditivo modificador de viscosidade - 1,0\% & $3,7 \mathrm{Kg}$ \\
\hline Relação Água / Cimento + Adições & 0,47 \\
\hline Teor de argamassa & $58 \%$ \\
\hline
\end{tabular}

Fonte: Autores.

A mistura do concreto ocorreu em betoneira estacionária de eixo inclinado e por um período necessário para formar uma massa homogênea com algumas interrupções para verificação da homogeneidade de acordo com a ABNT NBR 12655:2015. Para evitar a aglutinação do pigmento em contato com a água prejudicando a uniformidade, foi necessário incorporar na betoneira inicialmente os materiais secos, e depois, os materiais líquidos. Após a concretagem das amostras, elas permaneceram na câmara úmida de acordo com a ABNT NBR 9479:2006 até completarem 28 dias para o período de cura, e assim, realizar a desfôrma de maneira contínua e rápida.

Para a realização dos ensaios foram moldados corpos de prova cilíndricos conforme a ABNT NBR 5738:2015 com tamanho de $10 \mathrm{~cm}$ x $20 \mathrm{~cm}$ (diâmetro x altura), sendo 12 amostras para o ensaio de determinação da absorção de água, índice de vazios e massa específica (MAV); 12 amostras para o ensaio de determinação da absorção de água por capilaridade; e 16 amotras para o ensaio de compressão de corpos de prova cilíndricos, em um total de 40 corpos de prova.

\subsubsection{Ensaios de caracterização do concreto no estado fresco e endurecido}

Para a caracterização do concreto autoadensável dosado, foram realizados ensaios de caracterização das propriedades em estado fresco e endurecido utilizando os métodos especificados em Normas Brasileiras a seguir:

- Ensaio de determinação do espalhamento pelo Método do cone de Abrams - ABNT NBR 15823-2:2017;

- Ensaio de determinação da habilidade passante pelo Método do anel J - ABNT NBR 15823-3:2017;

- Ensaio de determinação da habilidade passante pelo Método da caixa L - ABNT NBR 15823-4:2017;

- Ensaio de determinação do teor de ar em concreto fresco pelo Método pressométrico - ABNT NBR NM 47:2002;

- Ensaio de determinação da absorção de água, índice de vazios e massa específica (MAV) - ABNT NBR 9778:2005;

- Ensaio de determinação da absorção de água por capilaridade - ABNT NBR 9779:2012;

- Ensaio de compressão de corpos de prova cilíndricos - ABNT NBR 5739:2018. 


\section{RESULTADOS E DISCUSSÕES}

\subsection{Ensaio de determinação do espalhamento pelo Método do cone de Abrams}

Este ensaio permitiu a avaliação da fluidez do concreto autoadensável em fluxo livre perante a ação de seu próprio peso, e determinou o índice de estabilidade visual do concreto autoadensável. Após a remoção do cone de Abrams e o espalhamento, observou-se que todas as misturas sem e com pigmento não apresentaram exsudação nas bordas e os agregados estavam espalhamos uniformemente, confirmando a adequada dosagem e compactação dos materiais durante o amassamento, o que contribui para a diminuição da porosidade no concreto. Na Figura 3 encontram-se as etapas do ensaio.

Figura 3 - Ensaio pelo Método do cone de Abrams: (a) Concreto sem pigmento; (b) Concreto com pigmento amarelo; (c) Concreto com pigmento azul; (d) Concreto com pigmento verde.
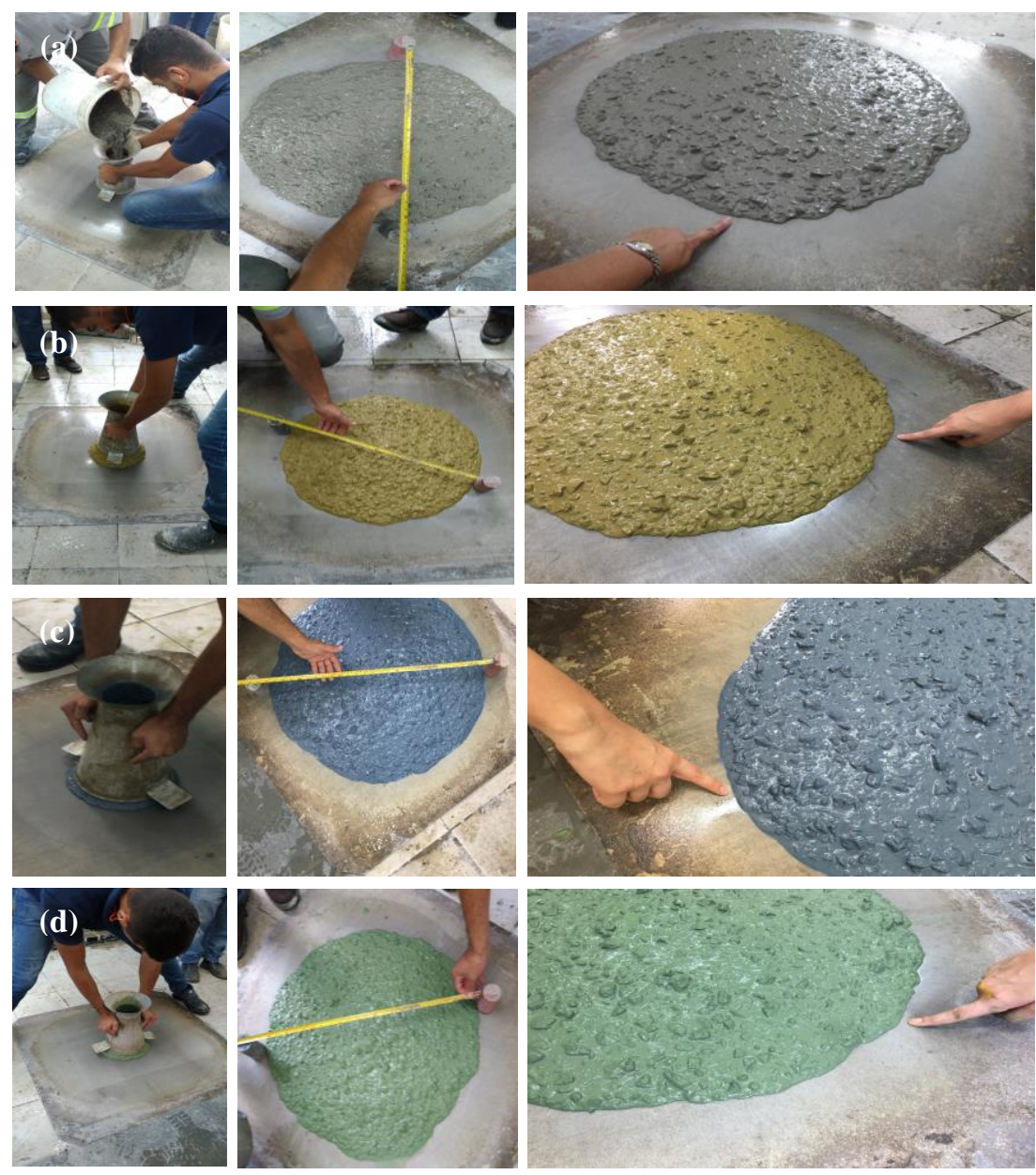

Fonte: Autores.

A classe de espalhamento "slump-flow" de todas as misturas foram classificadas em SF 2 de acordo com a Tabela 1 da ABNT NBR 15823-1:2017 por apresentarem espalhamento conferindo a propriedade autoadensável. Os valores do espalhamento podem ser conferidos na Tabela 3 abaixo.

Tabela 3 - Espalhamento "slump-flow" das misturas.

\begin{tabular}{c|c}
\hline Misturas & Espalhamento $(\mathrm{mm})$ \\
\hline Concreto sem pigmento & 680 \\
\hline Concreto com pigmento amarelo & 660 \\
\hline Concreto com pigmento azul & 730 \\
\hline Concreto com pigmento verde & 660 \\
\hline
\end{tabular}

Fonte: Autores. 
Já em relação a classe de viscosidade plástica aparente sob fluxo livre todas as misturas foram classificadas em VS 1 de acordo com a Tabela 2 da ABNT NBR 15823-1:2017. Isto significa que o concreto possui um bom acabamento superficial, ou seja, ele é adequado para ser usado como concreto aparente. Em relação ao índice de estabilidade visual todas as misturas foram classificadas como IEV 0 - Altamente estável de acordo com a Tabela 3 da ABNT NBR 158231:2017 por não terem a evidência de segregação ou exsudação.

\subsection{Ensaio de determinação da habilidade passante pelo Método do anel J}

Este ensaio determininou da habilidade passante do concreto autoadensável em fluxo livre, pelo anel J. Por meio deste ensaio foi possível verificar e confirmar a capacidade do concreto autoadensável de fluir dentro do molde, passando entre as barras de aço do anel J, sem obstrução do fluxo ou segregação. A classe de habilidade passante pelo anel J sob fluxo livre apresentada pela mistura sem pigmento foi classificada como PJ 1 de acordo com a Tabela 4 da ABNT NBR 15823-1:2017, revelando que a aplicação deste concreto é adequada para a maioria das aplicações correntes. Na Figura 4 é possível compreender este ensaio.

Figura 4 - Ensaio pelo Método do anel J.
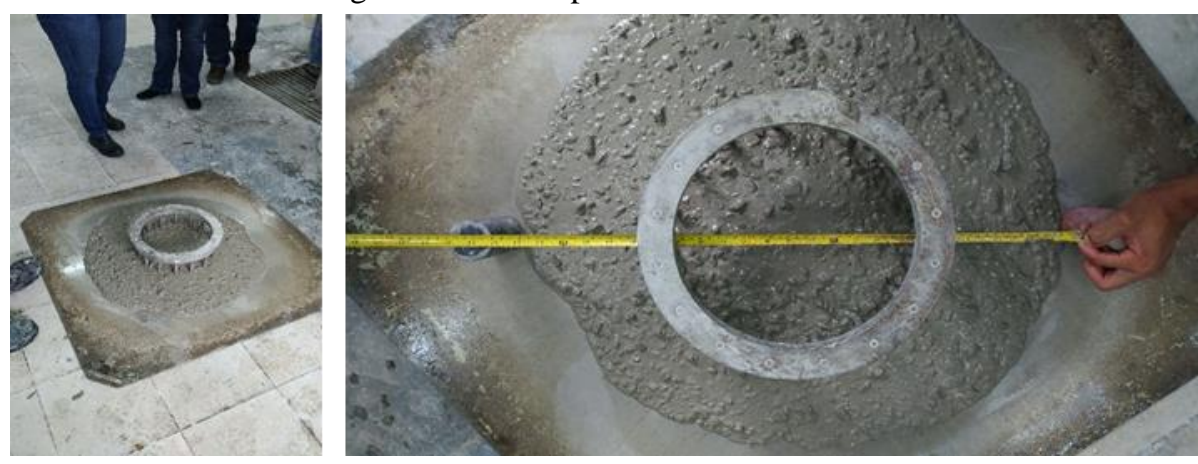

Fonte: Autores.

\subsection{Ensaio de determinação da habilidade passante pelo Método da caixa $L$}

Este ensaio determinou a habilidade passante em fluxo confinado do concreto autoadensável usando a caixa L. Por meio deste ensaio a mistura sem pigmento apresentou habilidade passante de 0,85 comprovando a capacidade do concreto autoadensável de fluir sem perder a uniformidade por meio de espaços confinados. A classe de habilidade passante pela caixa L sob fluxo confinado foi classificada como PL 2 de acordo com a Tabela 5 da ABNT NBR 15823-1:2017, indicando que o uso deste concreto é adequado para a maioria das aplicações correntes. Na Figura 5 é possível verificar o ensaio.

Figura 5 - Ensaio pelo Método da caixa L.
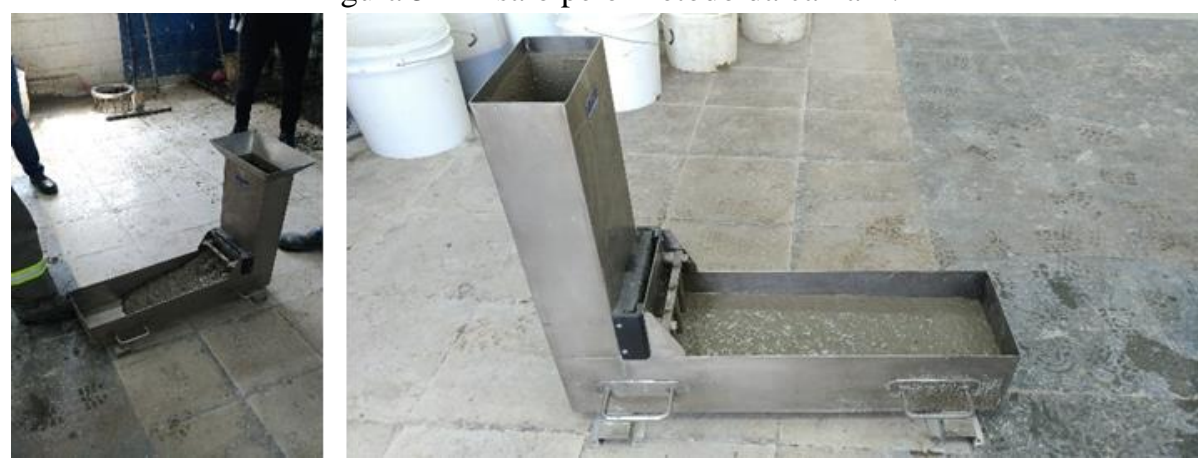

Fonte: Autores.

\subsection{Ensaio de determinação do teor de ar em concreto fresco pelo Método pressométrico}

Este ensaio determinou o teor de ar incorporado na mistura sem pigmento no estado fresco conforme ABNT NBR NM 47:2002. O valor obtido da massa específica foi de $2.438 \mathrm{~kg} / \mathrm{m}^{3}$ e o teor de ar na mistura foi de $0,7 \%$. 


\subsection{Ensaio de determinação da absorção de água, índice de vazios e massa específica (MAV)}

Este ensaio determinou a absorção de água, o índice de vazios por imersão e fervura, e a massa específica de concreto endurecido e foi realizado com todas as amostras sem e com pigmento aos 28 dias de idade de acordo com ABNT NBR 9778:2005. Nas Figuras 6 e 7 são apresentados respectivamente, os resultados da absorção de água por imersão - que é o processo pelo qual a água é levada e tende a ocupar os poros permeáveis do corpo sólido; e o índice de vazios - que é a relação entre o volume de poros permeáveis e o volume total da amostra.

Figura 6 - Resultado do ensaio de absorção de água.

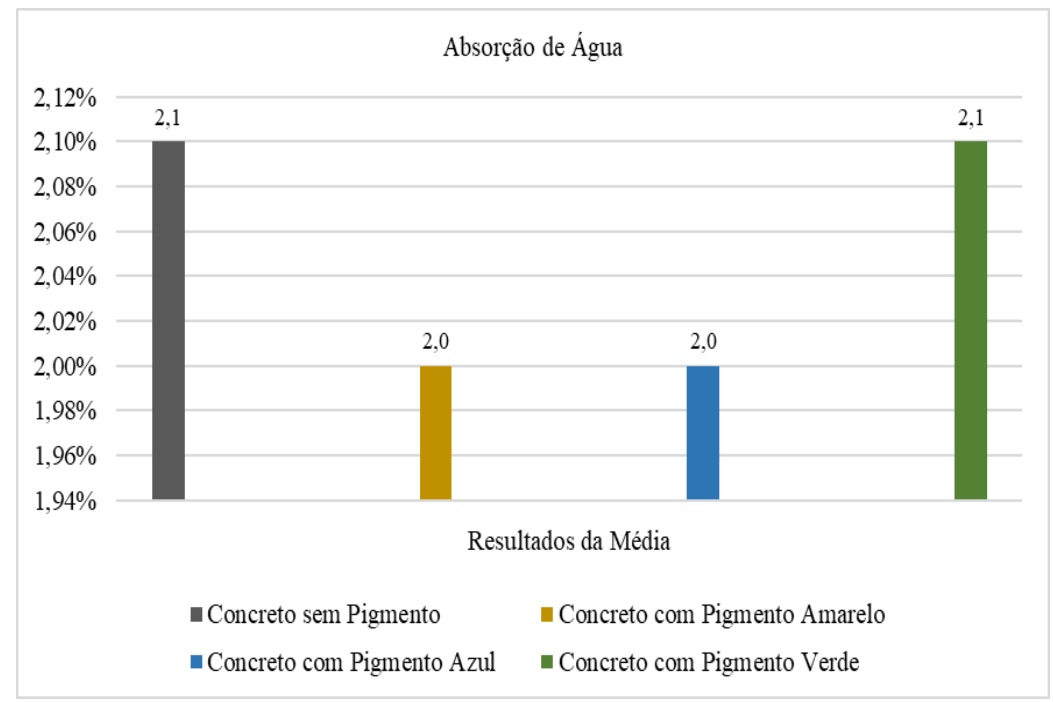

Fonte: LMCC - IPT (2019).

Figura 7 - Resultado do ensaio de índice de vazios.

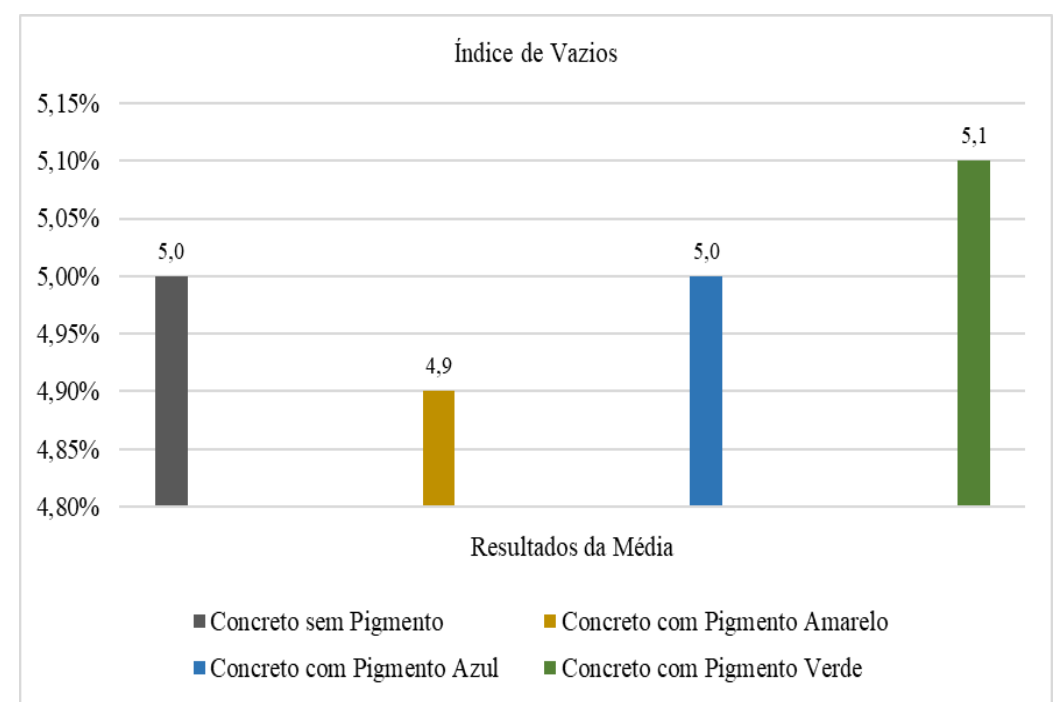

Fonte: LMCC - IPT (2019).

Os resultados indicaram um baixo índice de poros nas amostras com pigmento, e consequentemente uma baixa absorção de água. Em comparação com a amostra sem pigmento que apresentou uma maior absorção de água com resultados da média de $2,1 \%$, as demais amostras com pigmento apresentaram resultado inferior, com exceção da amostra com pigmento verde que apresentou resultado idêntico ao concreto sem pigmento.

Já em relação aos resultados da média do índice de vazios, a amostra sem pigmento apresentou 5,0\% e as demais amostras com pigmento apresentaram resultados da média igual ou inferior ao concreto sem pigmento, com exceção da amostra com pigmento verde com $5,1 \%$, apresentando um maior valor em comparação a amostra sem pigmento. 
A amostra com pigmento verde, por apresentar resultados da média igual ou superior ao concreto sem pigmento, em relação a absorção de água e índice de vazios, refletiu em um resultado da média da massa específica maior com 2,58 $\mathrm{kg} / \mathrm{dm}^{3}$ em comparação as demais amostras que apresentaram média de $2,57 \mathrm{~kg} / \mathrm{dm}^{3}$. Na Tabela 4 é possível visualizar todos os resultados do ensaio de MAV sendo os dados mencionados na coluna "indiv." aos valores das medições individuais, e na coluna "média" expressa a média entre esses valores.

Tabela 4 - Todos os resultados do ensaio de MAV.

\begin{tabular}{|c|c|c|c|c|c|c|c|c|c|c|}
\hline \multirow[t]{2}{*}{ Corpos de prova } & \multicolumn{2}{|c|}{$\begin{array}{l}\text { Absorção de } \\
\text { água } \\
(\%) \\
\end{array}$} & \multicolumn{2}{|c|}{$\begin{array}{c}\text { Índice de } \\
\text { vazios } \\
(\%) \\
\end{array}$} & \multicolumn{2}{|c|}{$\begin{array}{c}\text { Massa específica } \\
\text { da amostra seca } \\
\left(\mathrm{kg} / \mathrm{dm}^{3}\right)\end{array}$} & \multicolumn{2}{|c|}{$\begin{array}{c}\text { Massa específica da } \\
\text { amostra saturada } \\
\left(\mathrm{kg} / \mathrm{dm}^{3}\right)\end{array}$} & \multicolumn{2}{|c|}{$\begin{array}{c}\text { Massa } \\
\text { específica real } \\
\left(\mathrm{kg} / \mathrm{dm}^{3}\right) \\
\end{array}$} \\
\hline & Indiv. & Média & Indiv. & Média & Indiv. & Média & Indiv. & Média & Indiv. & Média \\
\hline \multirow{3}{*}{$\begin{array}{l}\text { Concreto sem } \\
\text { pigmento }\end{array}$} & 2,1 & \multirow{3}{*}{2,1} & 5,0 & \multirow{3}{*}{5,0} & 2,45 & \multirow{3}{*}{2,45} & 2,50 & \multirow{3}{*}{2,50} & 2,58 & \multirow{3}{*}{2,57} \\
\hline & 2,0 & & 4,9 & & 2,46 & & 2,51 & & 2,58 & \\
\hline & 2,1 & & 5,1 & & 2,43 & & 2,48 & & 2,56 & \\
\hline \multirow{3}{*}{$\begin{array}{l}\text { Concreto com } \\
\text { pigmento } \\
\text { amarelo } \\
\end{array}$} & 2,1 & \multirow{3}{*}{2,0} & 5,1 & \multirow{3}{*}{4,9} & 2,43 & \multirow{3}{*}{2,45} & 2,48 & \multirow{3}{*}{2,50} & 2,56 & \multirow{3}{*}{2,57} \\
\hline & 1,9 & & 4,8 & & 2,48 & & 2,53 & & 2,60 & \\
\hline & 2,0 & & 4,9 & & 2,43 & & 2,48 & & 2,56 & \\
\hline \multirow{3}{*}{$\begin{array}{l}\text { Concreto com } \\
\text { pigmento azul }\end{array}$} & 2,0 & \multirow{3}{*}{2,0} & 4,9 & \multirow{3}{*}{5,0} & 2,44 & \multirow{3}{*}{2,44} & 2,49 & \multirow{3}{*}{2,49} & 2,57 & \multirow{3}{*}{2,57} \\
\hline & 2,1 & & 5,1 & & 2,44 & & 2,49 & & 2,57 & \\
\hline & 2,0 & & 4,9 & & 2,44 & & 2,49 & & 2,57 & \\
\hline \multirow{3}{*}{$\begin{array}{l}\text { Concreto com } \\
\text { pigmento verde }\end{array}$} & 2,0 & \multirow{3}{*}{2,1} & 5,0 & \multirow{3}{*}{5,1} & 2,46 & \multirow{3}{*}{2,45} & 2,51 & \multirow{3}{*}{2,50} & 2,58 & \multirow{3}{*}{2,58} \\
\hline & 2,0 & & 5,0 & & 2,47 & & 2,52 & & 2,60 & \\
\hline & 2,2 & & 5,2 & & 2,42 & & 2,47 & & 2,55 & \\
\hline
\end{tabular}

Fonte: LMCC - IPT (2019).

É possível considerar que o pigmento incorporado a mistura do concreto, na maior parte das vezes, colabora para o preenchimento dos poros do concreto, em consequência do diâmetro das suas partículas, aperfeiçoando as propriedades do concreto e contribuindo para a durabilidade. Sendo que, as diferenças entre os resultados obtidos das amostras são mínimas demostrando que o pigmento não influenciou negativamente nestas propriedades.

\subsection{Ensaio de determinação da absorção de água por capilaridade}

Este ensaio determinou a absorção de água por meio da ascensão capilar de concreto endurecido e foi realizado com todas as amostras sem e com pigmento aos 28 dias de idade conforme ABNT NBR 9779:2012. Os resultados obtidos no ensaio de absorção de água por capilaridade estão apresentados na Tabela 5. Correspondem à altura da ascensão capilar máxima, com a média em centímetros, após o rompimento dos corpos de prova por compressão diametral. Com isto, pode-se verificar a distribuição da água no interior das amostras.

Tabela 5 - Resultados do ensaio da absorção de água por capilaridade.

\begin{tabular}{|c|c|c|}
\hline \multirow{2}{*}{ Corpos de prova } & \multicolumn{2}{|c|}{ Altura da ascensão capilar máxima $(\mathrm{cm})$} \\
\hline & Individual & Média \\
\hline \multirow{3}{*}{ Concreto sem pigmento } & 14 & \multirow{3}{*}{13} \\
\hline & 14 & \\
\hline & 11 & \\
\hline \multirow{3}{*}{ Concreto com pigmento amarelo } & 11 & \multirow{3}{*}{11} \\
\hline & 13 & \\
\hline & 9 & \\
\hline \multirow{3}{*}{ Concreto com pigmento azul } & 11 & \multirow{3}{*}{11} \\
\hline & 11 & \\
\hline & 11 & \\
\hline \multirow{3}{*}{ Concreto com pigmento verde } & 11 & \multirow{3}{*}{12} \\
\hline & 11 & \\
\hline & 14 & \\
\hline
\end{tabular}

Fonte: LMCC - IPT (2019). 
Nas Figuras 8 e 9 apresentam-se, respectivamente, os resultados da absorção de água por capilaridade com determinação da massa saturada dos corpos de prova com 3h, 6h, 24h, 48h e 72h, a partir da colocação das amostras em contato com a água; e os resultados da altura da ascensão capilar nos corpos de prova.

Figura 8 - Resultados da absorção de água por capilaridade.

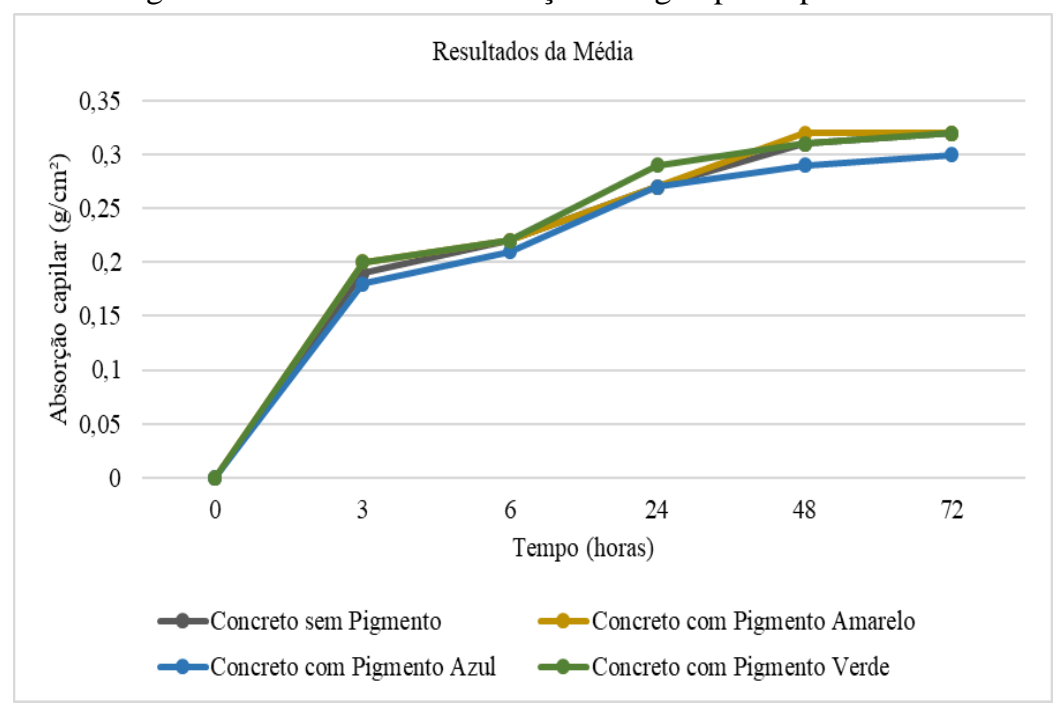

Fonte: LMCC - IPT (2019).

Figura 9 - Resultados da altura da ascensão capilar.

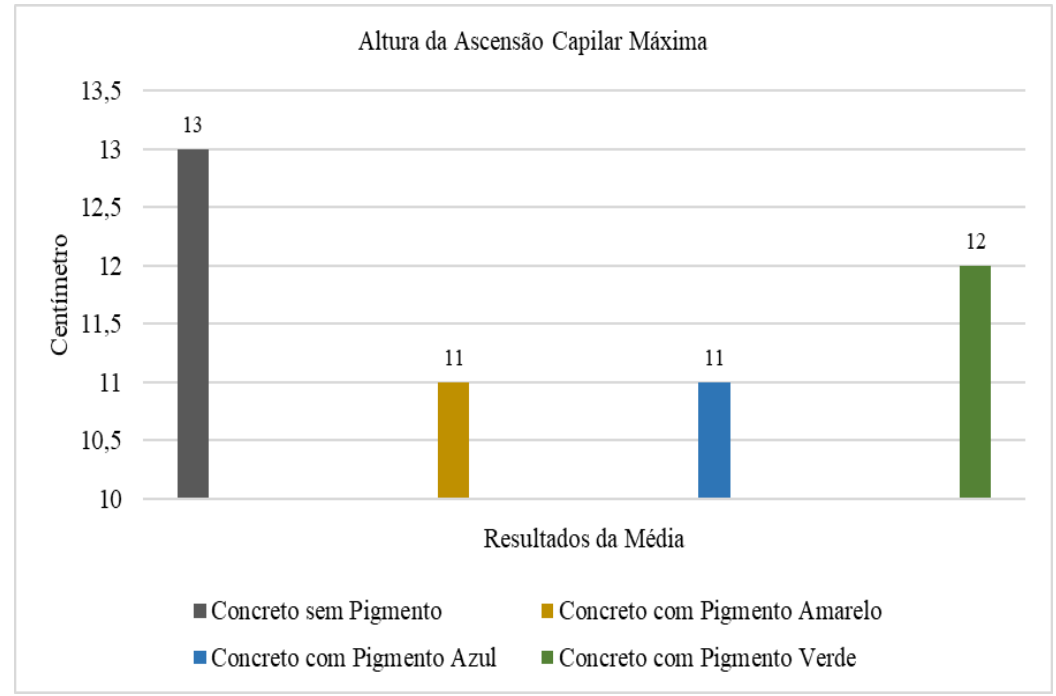

Fonte: LMCC - IPT (2019).

Todos os concretos com pigmento apresentaram de maneira geral baixa absorção de água, em relação ao concreto sem pigmento, com valores muito próximos durante o ensaio, atingindo o objetivo inicial em relação a qualidade do concreto. Quanto menor a taxa de absorção de água presente no concreto, maior será sua resistância aos agentes externos do ambiente que comprometem a durabilidade. A baixa porosidade dos concretos é importante para sua durabilidade, pois diminui a permeabilidade do concreto

Nota-se que os resultados nos concretos com pigmento a média da altura da ascensão capilar máxima foi menor, em comparação com o concreto sem pigmento que apresentou o maior valor de $13 \mathrm{~cm}$. Este resultado indica que os concretos com pigmento podem apresentar poucos baixa capilaridade. Pelos resultados, observa-se que o emprego do pigmento na mistura do concreto pode colaborar para o preenchimento dos poros devido ao pequeno diâmetro das partículas, contribuindo para a melhoria das propriedades do concreto relacionada a durabilidade. 


\subsection{Ensaio de compressão de corpos de prova cilíndricos}

Este ensaio determinou a resistência à compressão axial dos corpos de prova cilíndricos moldados conforme a $\mathrm{ABNT}$ NBR 5738:2015. Em todas as amostras com e sem pigmento e em ambas as idades, a ruptura ocorreu na interface do concreto com o agregado graúdo, indicando um pasta de alta resistência, com tipo de ruptura "Tipo A" dos corpos de prova em sua maioria. Os resultados dos ensaios de resistência à compressão axial estão compilados na Figura 10.

Figura 10 - Resultados do ensaio de resistência à compressão aos 7 e 28 dias de idade.

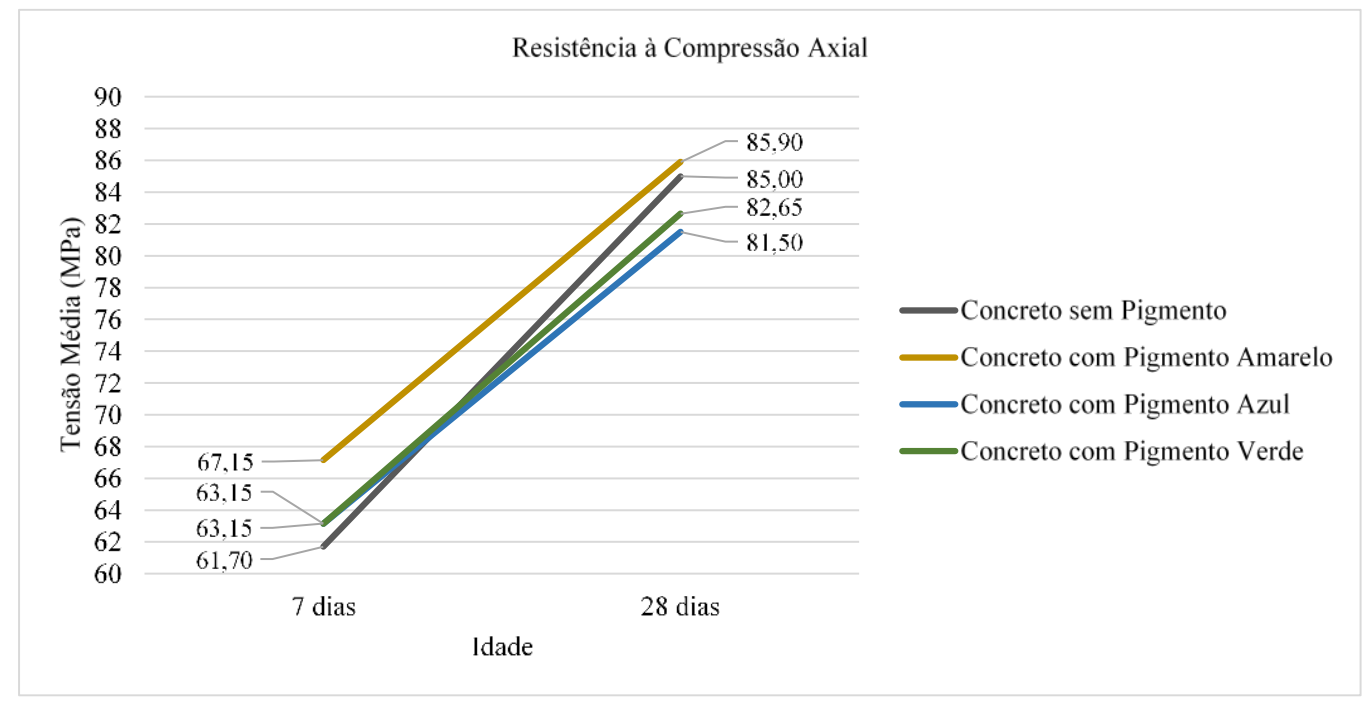

Fonte: LMCC - IPT (2019).

Pode-se notar que todas as amostras superaram a resistência especificada no cálculo de dosagem de 60 MPa aos 28 dias. Outra constatação possível é de que os concretos pigmentados apresentaram resistência à compressão superior à do concreto sem pigmento. Aos 7 dias de idade, a amostra com pigmento amarelo apresentou um aumento de 8,83\% na resistência à compressão em relação a amostra sem pigmento e as amostras com pigmento azul e verde apresentaram um aumento de 2,35\% ambos. Aos 28 dias de idade, a amostra com pigmento amarelo apresentou um aumento de $1,05 \%$ na resistência em relação ao concreto sem pigmento, já as amostras com pigmento azul e verde apresentaram uma redução de $4,11 \%$ e $2,76 \%$ respectivamente em relação a amostra sem pigmento.

Justifica-se o resultado observado pelo aumento da quantidade de finos na mistura (em relação ao concreto sem pigmento), graças à incorporação do pigmento, reduzindo a quantidade de poros dos concretos, e consequentemente, aumentando sua resistência. Os resultados dos ensaios de capilaridade corroboram esse panorama, bem como estão de acordo com o explicitado pela bibliografia, que aponta para um ganho de resistência em dosagens que não ultrapassem o ponto de saturação (HOSPODAROVA, 2015).

\section{CONCLUSÕES}

O desempenho de uma edificação envolvendo concreto aparente pigmentado depende sobremaneira da dosagem do traço de concreto, a qual é determinante para aspectos de durabilidade e vida útil longevas. Evidentemente considera-se também a agressividade do ambiente a qual a edificação estará exposta. Logo, pode-se afirmar que é possível projetar um concreto pigmentado adequado para resistir às manifestações patológicas diversas, ao longo de sua vida útil, desde que controlada as suas propriedades físico-mecânicas.

Neste estudo, tomando-se como base os resultados obtidos do concreto referência (sem pigmento), pôde-se concluir que:

- Os concretos com pigmento apresentaram absorção de água e índice de vazios inferior nos ensaios de MAV e absorção por capilaridade, com ressalva do concreto pigmentado na cor verde que manifestou uma absorção de água igual e índice de vazios superior. Mas, as diferenças entre os resultados dos concretos em questão são mínimas denotando que o pigmento não influenciou negativamente nestas propriedades;

- A utilização do pigmento na mistura não interferiu na fluidez do concreto, não comprometendo a consistência e certificando a propriedade autoadensável da mistura proposta pelo traço definido; 
- A resistência a compressão não foi afetada pelo emprego do pigmento, pelo contrário, os concretos apresentaram uma alta resistência aos 28 dias de idade, com exceção do concreto pigmentado na cor azul em comparação as demais amostras, foi o concreto com a menor tensão média. Supõe-se que o tipo de pigmento influenciou no resultado, relembrando que refere-se de um concreto com baixa relação água / cimento e com resistência mecânica acima de $60 \mathrm{MPa}$ já aos 7 dias de idade;

- A resistência a compressão não foi afetada pelo emprego do pigmento, pelo contrário, os concretos apresentaram uma alta resistência aos 28 dias de idade, com exceção do concreto pigmentado na cor azul em comparação as demais amostras, foi o concreto com a menor tensão média;

- Embora não se tenha apresentado os resultados da análise granulométrica e caracterização dos pigmentos, os mesmos foram realizados na ocasião dos estudos de dosagem. Com base nesses resultados, somados aos obtidos nesse estudo, constatou-se que o empacotamento das partículas dos pigmentos pode ter influenciado na diferença de resistência à compressão dos concretos analisados. Isto porque, cada cor do pigmento tem partículas de formatos e tamanho diferenciados - sendo as partículas do pigmento hidróxido de ferro (amarelo) em forma de agulha e a dos pigmentos óxido de cobalto e cromo (azul e verde) em forma cúbica a esférica (BARRERA et al., 2002) - e a distribuição granulométrica dos materiais constituintes do concreto, rege o empacotamento destas partículas e consequentemente, sua resistência à compressão no estado endurecido. Porém, independente disto, obteve-se resistências acima de $80 \mathrm{MPa}$, muito superior ao que inicialmente se pretendia, de $60 \mathrm{MPA}$.

Depara-se, por vezes, com muita informação equivocada relacionada ao tema, no que tange principalmente a diminuição de resistência mecânica (SESSA et al., 2018), quando do uso de concreto pigmentado, o que não foi um fato neste estudo.

Enfim, a dosagem adotada foi extremamente satisfatória em relação à durabilidade e à resistência mecânica do concreto pigmentado, podendo assim garantir a qualidade da estética em relação à homogeneidade da mistura, levando em consideração que o aspecto visual da cor é um dos principais objetivos deste material.

\section{AGRADECIMENTOS}

Ao Laboratório de Materiais de Construção Civil (LMCC) do Instituto de Pesquisas Tecnológicas (IPT) pelos ensaios realizados.

À Votorantim pelo fornecimento de material e disponibilização do laborarótio.

À Lanxess pelo fornecimento do pigmento.

\section{REFERÊNCIAS}

ASSOCIAÇÃO BRASILEIRA DE NORMAS TÉCNICAS. NBR NM 47: Concreto - Determinação do teor de ar em concreto fresco - Método pressométrico. Rio de Janeiro, 2002.

ASSOCIAÇÃO BRASILEIRA DE NORMAS TÉCNICAS. NBR 9778: Argamassa e concreto endurecidos Determinação da absorção de água, índice de vazios e massa específica. Rio de Janeiro, 2005.

ASSOCIAÇÃO BRASILEIRA DE NORMAS TÉCNICAS. NBR 9479 : Argamassa e concreto - Câmaras úmidas e tanques para a cura de corpos-de-prova. Rio de Janeiro, 2006.

ASSOCIAÇÃO BRASILEIRA DE NORMAS TÉCNICAS. NBR 9779: Argamassa e concreto endurecidos Determinação da absorção de água por capilaridade. Rio de Janeiro, 2012.

ASSOCIAÇÃO BRASILEIRA DE NORMAS TÉCNICAS. NBR 5738: Concreto - Procedimento para moldagem e cura de corpos de prova. Rio de Janeiro, 2015.

ASSOCIAÇÃO BRASILEIRA DE NORMAS TÉCNICAS. NBR 12655: Concreto de cimento Portland - Preparo, controle, recebimento e aceitação - Procedimento. Rio de Janeiro, 2015.

ASSOCIAÇÃO BRASILEIRA DE NORMAS TÉCNICAS. NBR 15823-1: Concreto autoadensável - Parte 1: Classificação, controle e recebimento no estado fresco. Rio de Janeiro, 2017.

ASSOCIAÇÃO BRASILEIRA DE NORMAS TÉCNICAS. NBR 15823-2: Concreto autoadensável - Parte 2: Determinação do espalhamento, do tempo de escoamento e do índice de estabilidade visual - Método do cone de Abrams. Rio de Janeiro, 2017.

ASSOCIAÇÃO BRASILEIRA DE NORMAS TÉCNICAS. NBR 15823-3: Concreto autoadensável - Parte 3: Determinação da habilidade passante - Método do anel J. Rio de Janeiro, 2017. 
ASSOCIAÇÃO BRASILEIRA DE NORMAS TÉCNICAS. NBR 15823-4: Concreto autoadensável - Parte 4: Determinação da habilidade passante - Métodos da caixa L e da caixa U. Rio de Janeiro, 2017. ASSOCIAÇÃO BRASILEIRA DE NORMAS TÉCNICAS. NBR 5739: Concreto - Ensaio de compressão de corpos de prova cilíndricos. Rio de Janeiro, 2018.

AGUIAR, Cíntia Alves. Concreto de cimento Portland branco estrutural: análise da adição de pigmentos quanto à resistência à compressão. Dissertação de Mestrado. UFRGS. Porto Alegre, 2006.

BARRERA, Hugo V.; ANABALÓN, Alejandra G.; GUTIÉRREZ, Samuel H. Hormigones decorativos. Universidad de Santiago de Chile, 2002.

COELHO, F. C. A.; RUIZ, J. C.; GÓMEZ, J. F.; SÁNCHEZ, P. L. Estudio de la variación de color y la durabilidad en hormigones vistos con adición de pigmentos somentidos a distintos tratamientos de exposición ambiental. In: Cuadernos INTEMAC, n. 43, 4-41, 2002.

DE MENDONÇA, A. C. S.; DA ROCHA, R. A. S.; GOMES, R. S.; GOMES, A. L. S.; DE ASSIS NETO, P. C.; GURGEL, S. H. A. Avaliação da eficiência do uso do concreto colorido aplicado em paredes. Revista InterScientia, 6.1, 147-171, 2018

HOSPODAROVA, V.; JUNAK, J.; STEVUlOVA, N. Color pigments in concrete and their properties. Pollack Periodica, v. 10, n. 3, p. 143-151, 2015.

PASSUELO, Alexandra. Análise e parâmetros influentes na cromaticidade e no comportamento mecânico de concretos à base de comento branco. 133f. Dissertação (mestrado em Engenharia Civil) - Escola de engenharia, Universidade Federal do Rio Grande do Sul, Porto Alegre, 2004.

PIOVESAN, Angela Zamboni. Estudo sobre a influência da adição de pigmentos em propriedades de durabilidade e na cromacidade do concreto de cimento Portland branco. Dissertação (Mestrado em Engenharia) - Escola de Engenharia, Programa de Pós-graduação em Engenharia Civil, Universidade Federal do Rio Grande do Sul, Porto Alegre, 2009.

SESSA, G.; OLIVEIRA, A. M. Influência de pigmentos inorgânicos na degradação da cor de concretos de cimento Portland branco. In: $3^{\circ}$ Encontro Luso-Brasileiro de Degradação em Estruturas de Concreto - DEGRADA 2018. São Carlos, SP, 2018.

SOUSA, G. M.; RAMALHO, J. F.: OLIVEIRA, K. R. Aplicabilidade do concreto colorido na construção civil no município de Teófilo Otoni. Trabalho de Conclusão de Curso - Engenharia Civil - Universidade Federal dos Vales do Jequitinhonha e Mucuri, Teófilo Otoni, 2018.

VALENÇA, J. V.; PRISZKULNIK, S. Concreto Colorido: Influência da adição de pigmentos e suas aplicações. Universidade Presbiteriana Mackenzie. XIII Jornada de Iniciação Científica e VII Mostra de Iniciação Tecnológica, 2017. 